\title{
The risks of minor head injury in the warfarinised patient
}

\author{
A P Volans
}

\begin{abstract}
The risk factors affecting intracranial haemorrhage in warfarinised patients are described and an attempt made to calculate the risk of haemorrhage in warfarinised patients with minor head injuries. Using the data from studies of patients with spontaneous haemorrhage while taking warfarin, guidelines for treatment and given and the likely outcome predicted. ( $F$ Accid Emerg Med 1998;15:159-161)
\end{abstract}

Keywords: warfarin; head injury

The risk of spontaneous intracranial bleeding in patients taking oral anticoagulants is well described. Much less has been written about the effect of oral anticoagulation on the risk of intracranial bleeding following head injury.

In one year, three cases of severe intracranial haemorrhage following apparently trivial head injuries were seen in one city centre accident and emergency unit (Royal Hallamshire Hospital, Sheffield). This led to a search for guidelines about risks, assessment, and management of patients presenting with minor head injury while taking warfarin.

To produce useful guidelines, the answers to several questions are needed: (1) are there any clinical features that select for high risk patients? (2) What is the time scale of haematoma development? (3) What are the indications to admit for observation in these patients? (4) What are the indications to perform computerised tomography (CT) in these patients? (5) When would be the most appropriate time for CT? (6) Are these patients more likely to have a poor prognosis? (7) Does intervention affect the natural history of the injury?

\section{Methods}

The clinical data from the three cases seen at this unit were compared with those of two published case reports. ${ }^{12}$ A further Medline search was performed using the terms "anticoagulation," "warfarin," "intracranial," and "intracerebral haemorrhage."

To obtain an estimate of the size of the Accident and

Emergency Medicine, Scarborough Hospital, Woodlands Drive,

Scarborough YO12 OHS, UK A P Volans

Correspondence to: Mr A P Volans, consultant in accident and emergency.

Accepted for publication 15 December 1997 terised records were examined on a Microsoft Access database. Patients attending with head injury in the retirement age group, 65 years and over, were extracted, since our three cases were all in this age group.

\section{Results}

The three patients attending this unit all gave a history of a minor head injury following a fall and presented with headache up to three days after the event. While they were in the department, two patients then deteriorated rapidly because of intracerebral haemorrhage and subsequently died.

Two published case reports were identified giving clinical details about eight similar patients. The details are compared in table 1 .

The search of data from Sheffield over a single year showed that of 50000 attendances, there were 215 patients over the age of 65 with a coding for head injury. The three described cases were within this group, giving a prevalence of $1.3 \%$ in the risk population.

\section{Discussion}

THE SIZE OF THE PROBLEM

Currently, approximately $0.4 \%$ of adults$2.4 \%$ of those over $60^{3}$ and $5 \%$ over 80 years of age ${ }^{4}$-are diagnosed as suffering from atrial fibrillation. There has been a significant campaign within the medical establishment to treat these patients with warfarin to protect them from the thromboembolic complications of their atrial fibrillation. Warfarin is also prescribed for patients with valvar disease, after valvar surgery and coronary artery bypass grafting, and for the treatment of thromboembolic, peripheral vascular, and cerebrovascular disease. The number of such patients in the community is unknown but is significant and growing.

It would be expected that five patients in our over-65 minor head injury group would have atrial fibrillation and an unknown number may have other indications for anticoagulant treatment. The risk population for this department would therefore appear at most to be in the tens rather than the hundreds.

A recognised major complication of warfarin treatment is spontaneous intracranial haemorrhage. What is not clear is how warfarin affects the risk of apparently minor head injury and what should be the response of $A \& E$ practitioners to the patient on warfarin who presents with such an injury.

The bulk of the published reports concerning complications of anticoagulants describes the risks of spontaneous bleeding. The role of head trauma is not frequently reported.
Placing a patient on warfarin increases the patient's risk of spontaneous intracranial haemorrhage five- to 10 -fold. ${ }^{56}$ The overall risk of fatal intracranial haemorrhage while on warfarin is between $0.6 \%$ and $1.4 \%$ per year, ${ }^{367}$ with a further $3 \%$ risk of major haemorrhage and a $9 \%$ risk of all haemorrhage. The 
Table 1 Clinical details of case reports

\begin{tabular}{llllllll}
\hline Patient & Age (years) & $\begin{array}{l}\text { Reason for } \\
\text { warfarin }\end{array}$ & $\begin{array}{l}\text { Time to } \\
\text { symptoms }\end{array}$ & Symptoms on attending & PT ratio & Lesion & Outcome \\
\hline 1 & 73 & Valve & $60 \mathrm{~h}$ & Headache & 2.2 & ICH & Died \\
2 & 65 & PE & $44 \mathrm{~h}$ & Transient LOC & $?$ & ICH & Died \\
3 & 72 & DVT & $62 \mathrm{~h}$ & Headache & 2.2 & SDH & Survived \\
4 & 70 & AF & $48 \mathrm{~h}$ & Headache & 2.5 & ICH & Survived \\
5 & 67 & Valve & $6 \mathrm{~h}$ & 5 min PTA & 4.2 & SDH & Died \\
6 & 69 & DVT & Immediate & Coma, minor HI & 4.6 & SDH & Died \\
7 & 75 & AF & Immediate & Coma, minor HI & 3.4 & SDH & Died \\
8 & 65 & PE & $?$ & Coma, minor HI & 2.9 & SDH & Died \\
9 & 58 & CABG & Immediate & Headache (shook head) & 10.6 & SAH & Survived \\
10 & 66 & AF & Immediate & Spont hemiplegia & $>10$ & SDH & Died \\
11 & 57 & AF & Immediate & Spont coma & 5.5 & SDH & Died \\
\hline
\end{tabular}

Cases 1-3 were from this unit, 4 and 5 from Saab et al, ${ }^{1}$ 6-11 from Pople et al. ${ }^{2}$

AF, atrial fibrillation; CABG, coronary artery bypass graft; DVT, deep vein thrombosis; HI, head injury; ICH, intracranial haemorrhage; LOC, loss of consciousness; PE, pulmonary embolism; PTA, post-traumatic amnesia; SAH, subarachnoid haemorrhage; $\mathrm{SDH}$, subdural haematoma; spont, spontaneous.

risk appears to be highest during the first year of treatment, with a reported 10 -fold increase in risk compared with subsequent years. ${ }^{3}$

\section{RISK FACTORS}

All studies show that intracranial haemorrhage risk increases with increases in the level of anticoagulation..$^{389}$ In the majority of studies, this is the dominant risk factor.

Variability in control is also recognised, ${ }^{89}$ with its attendant risk of extreme elevations in anticoagulation, and this may also be the reason for the increased risk during the first year after the initiation of treatment.

Advancing age is often quoted as a risk factor, ${ }^{1011}$ possibly owing to the increased comorbidity, in particular hypertension and previous cerebrovascular ischaemia, which are in themselves recognised risk factors, as is the increased risk of drug interactions from polypharmacy.

Age in itself is recognised to add a threefold risk to heparin treatment, ${ }^{11}$ but reports are mixed for the effects of warfarin. Hyleck and Singer ${ }^{8}$ report that whereas age is a significant risk factor for subdural haematoma, with an odds ratio of 2.0 per decade, it does not achieve significance for intracerebral haemorrhage.

Being female is recorded as a risk factor, but this excess of risk is only seen in minor bleeds; there is parity between the sexes for major bleeds. ${ }^{12}$

The risk of a fall resulting in a significant injury has been studied. ${ }^{13}$ Ninety three stroke patients on anticoagulants suffered 131 falls without significant bleeding complications. The individual risk from falling in these high risk patients would appear to be below $1 \%$.

In the series of Hyleck and Singer, three of 121 patients studied had suffered a minor antecedent head injury. All three developed subdural haematomas.

PATTERNS OF BLEEDING

Fourteen per cent of primary intracranial haemorrhage is seen in association with anticoagulation. ${ }^{14}$. In a series of 68 patients with intracranial haemorrhage, 42 suffered spontaneous bleeds. The majority of these were on treatment for cerebrovascular disease. Twenty six post-traumatic bleeds were predominately in patients on warfarin for valvar disease. ${ }^{13}$
Another study of spontaneous intracranial haemorrhage reported that the risk factors differ for different patterns of bleeding. ${ }^{3}$ Intracerebral bleeding increases with any increase in the international normalised ratio (INR), the risk doubling with every 0.5 increase in INR. Other risk factors for intracerebral haemorrhage are previous cerebrovascular accident (odds ratio 3.0) and treatment for a heart valve (odds ratio 2.8).

In the same study it was reported that there was no increase in risk for subdural haematoma until the INR was greater than 4.0. The only other risk factor for subdural haematoma in that series was increased age (odds ratio 2.0 per decade).

\section{OUTCOME}

Of the 11 cases collected in this review, only three survived, giving a mortality of $73 \%$ matching the mortality of $77 \%$ seen by Mathieson et al, ${ }^{15}$ and $60 \%$ reported by Dahl et al. $^{7}$ Hylek and Singer ${ }^{10}$ reported a $46 \%$ mortality for intracerebral haemorrhage and $20 \%$ for subdural haemorrhage. Fogelholm et al found that case fatality was increased and neurological outcome worse in anticoagulated patients. ${ }^{14}$

CAN MANAGEMENT ALTER THE PROGNOSIS?

Given that the majority of intracranial haemorrhages are intracerebral $(70 \%)^{6}$ and that the surgical management of intracerebral haemorrhage is very limited, the primary route of improved care must be through prevention or reduction in the size of the haemorrhage.

A series has been reported comparing the effects of two regimens to reverse anticoagulation in patients with spontaneous intracranial haemorrhage. ${ }^{16}$ In a treatment group receiving prothrombin complex, the reversal was more complete and twice as rapid as in the group receiving fresh frozen plasma. The neurological deterioration was 10 times worse in patients in the plasma group.

It has been shown that strictly individualised initiation of anticoagulation results in lower incidences of bleeding complications during onset of treatment. ${ }^{17}$ Also monitoring anticoagulation by the INR, which standardises the reagents used in the coagulation assessment, reduces major bleeding events when compared 
Table 2 Theoretical risk of intracranial haemorrhage in warfarinised patients

\begin{tabular}{lll}
\hline Clinical pattern & Risk to normal patient ${ }^{20}$ & Risk to anticoagulated patient \\
\hline Fully oriented, no fracture & $1: 7866$ & $1: 800$ \\
Confused, no fracture & $1: 180$ & $1: 18$ \\
Fully oriented with fracture & $1: 45$ & $1: 4$ \\
Confused with fracture & $1: 5$ & $2: 1$ \\
\hline
\end{tabular}

with monitoring with the prothrombin time $(0 \% v 1.2 \%)^{18}$

\section{IMPLICATIONS FOR A\&E CARE}

Warfarin is recognised as a risk factor for spontaneous intracranial bleeding especially in patients at risk of cerebral ischaemia. It would be logical to assume that the risk of traumatic bleeding is also increased, although the absolute value of this increase is unknown. To answer this question will require a multicentre observational study to obtain sufficiently large numbers of patients.

Using the unproven assumption that the five- to 10-fold increase in risk of spontaneous intracranial haematoma is applicable to the risk calculation for intracranial haematoma in nonanticoagulated patients after head injury, we may use the data of Teasdale et al to calculate equivalent figures. ${ }^{19}$ These are shown in table 2.

If these figures are accurate then decisions become easier concerning admission and scan criteria.

Many patients attending the A\&E department after a head injury in this age group will attend because they are suffering symptoms. All three patients presented to this department with symptoms of persistent headache before their neurological deterioration made a lesion obvious. They all initially had a normal conscious level. In the series of Hyleck and Singer, headache was the most common presenting symptom.

\section{GUIDELINES}

Suggested guidelines for the screening of these patients should be as follows:

(1) All patients with a head injury should be questioned about the use of warfarin, particularly those over 60 years of age.

(2) All head injured patients on warfarin should have a measure of their anticoagulation, irrespective of their clinical state.

(3) Any patient with abnormally decreased coagulation should have this rapidly controlled in consultation with a haematologist, even if they have no symptoms.

(4) Any patient with any neurological symptoms, particularly headache, should undergo CT.

(5) Patients with abnormalities on $\mathrm{CT}$ require admission and may need urgent reversal of their anticoagulation under hospital condi- tions in an attempt to prevent deterioration. They will require the combined care of a haematologist and neurosurgeon. The control of the problem for which anticoagulation was instituted is beyond the scope of this paper.

(6) Patients with well controlled coagulation and no symptoms still have a perceived risk of 1:600. A very low threshold for CT investigation in these patients should be maintained. Given that the total numbers of such patients attending any one $A \& E$ unit are low, it may well be appropriate to subject all such patients to CT. However, this then raises the question of the timing of such a CT examination in the asymptomatic patient. A prospective study of such patients may clarify the risk group more accurately.

1 Saab M, Gray A, Hodgkinson D, Irfan M. Warfarin and the apparent minor head injury. J Accid Emerg Med 1996;13:208-9.

2 Pople IK, Stranjalis G, Nelson R. Anticoagulant-related intracranial haemorrhage. Br J Hosp Med 1993;49:428-9.

3 Drug and Therapeutics Bulletin 1996;34:41-4.

4 Adams JN, Gautam PC. Warfarin therapy in the elderly. $\mathrm{Br}$ J Hosp Med 1994;51:392-3.

5 Landenfeld CS, Beyth RJ. Anticoagulant related bleeding: clinical epidemiology, prediction and prevention. Am J Med 1993;95:315-28.

6 Hart RG, Boop BS, Anderson DC. Oral anticoagulants and intracranial haemorrhage. Facts and hypotheses. Stroke 1995;26:1471-7.

7 Dahl T, Abildgaard U, Sandset PM. Long term anticoagulant therapy in cerebrovascular disease: does bleeding outweigh benefit? J Intern Med 1995;237:323-9.

8 Fihn SD, McDonnell M, Martin D, Hanikoff J, Vermes D, Kent D, et al. Risk factors for complications of chronic anticoagulation. A multicentre study. Warfarin optimized outpatient follow-up study group. Ann Intern Med 1993;118:611-20.

9 Brigden ML. When bleeding complicates oral anticoagulant therapy. How to anticipate, investigate and treat. Postgrad Med 1995;98:153-65.

10 Hylek EM, Singer DE. Risk factors for intracranial haemorrhage in outpatients taking warfarin. Ann Intern Med 1994;120:897-902.

11 Beyht RJ, Landfeld CS. Anticoagulants in older patients. A safety perspective. Drugs and Ageing 1995;6:45-54.

12 Van de Meer FJ, Rosendaal FR, Vandenbrouke JP, Briet E Bleeding complications in oral anticoagulant therapy and analysis of risk factors. Arch Intern Med 1993;153:1557 62.

13 Stein J, Viramontes BE, Kerrigan DC. Fall related injuries in anticoagulated stroke patients during inpatient rehabilitation. Arch Phys Med Rehab 1995;76:840-3.

14 Fogelholm R, Eskola K, Kiminkinen T, Kunnamo I. Anticoagulant treatment as a risk factor for primary intracerebral haemorrhage. J Neurol Neurosurg Psychiatry 1992;55: 1121-4.

15 Mathiesen T, Benediktsdotttir K, Johnsson H, Lindqvist $M$ von Holst $H$. Intracranial traumatic and non-traumatic haemorrhagic complications of warfarin treatment. Acta haemorrhagic complications of

16 Freidriksson K, Norrving B, Strombald LG. Emergency reversal of anticoagulation after intracerebral haemorrhage. Stroke 1992;23:972-7.

17 Landefeld CS, Anderson PA, Guideline based consultation to prevent anticoagulant related bleeding. A randomised controlled trial in a teaching hospital. Ann Intern Med 1992;116:829-97.

18 Andrews TC, Peterson DW, Doeppenschmidt D, Foster JS, Lucca MJ, Deering JA, et al. Complications of warfarin therapy monitored by the international normalised ratio versus the prothrombin time ratio. Clin Cardiol 1995;18: 80-2.

19 Teasdale GM, Murray G, Anderson E, Mendelow AD, MacMillan R, Jennett $B$, et al. Risks of acute traumatic MacMillan $R$, Jennett $B$, et al. Risk of acute traumatic tions for manaing head injuries. BMJ 1990;300:363-7. 